\title{
Warm and Welcoming: Is It What We Say or How We Say It?
}

\author{
Herbert J. Zeh, MD, Sandra L. Wong, MD, and Martin J. Heslin, MD \\ Department of Surgery, University of Alabama at Birmingham, Birmingham, AL
}

As those responsible for the future design and implementation of the Society of Surgical Oncology (SSO) annual conference (H.J.Z. and M.J.H. as Chair and Vice Chair of the Scientific Program Committee, respectively), we read with great interest the article in this issue of Annals of Surgical Oncology evaluating unconscious bias in speaker introductions. Stewart et al. ${ }^{1}$ performed an observational study of video-archived introductions from the 2018 and 2019 SSO annual conferences, having previously noted gender biases at other large national meetings. Specifically, this work mirrors a recent study by Duma and colleagues which defined a "professional introduction" as one in which the speaker's professional title, followed by the speaker's full name or last name, was used ${ }^{2}$.

It is worth noting the innovative use of video review in this study. As a larger society, we have seen the impact that review of events captured real-time by video has on studying performance in complex situations and environments. Indeed, there is a growing body of literature that supports the power of video review for the assessment of surgical skill in the operating room ${ }^{3-5}$ as well as critical review of calls made on the field of play. Work in the operating room has established an association between technical performance and clinical outcomes and has implications for quality metrics and continuous quality improvement. Here, video review is used to evaluate the

(C) Society of Surgical Oncology 2020

First Received: 6 July 2020

Accepted: 8 July 2020;

Published Online: 22 July 2020

M. J. Heslin, MD

e-mail: mheslin@uabmc.edu performance of moderators during scientific sessions, with a focus on "nonprofessional" forms of speaker introductions.

First, it was gratifying that the authors did not find evidence of gender bias across nearly 500 speaker introductions at recent SSO annual meetings. In fact, the study concluded that the moderator used a nonprofessional introduction in just under $1 / 3$ of the introductions. This finding was observed to be more common for speakers who were trainees and in moderators as they increased in academic rank. The authors do point out that one of the limitations of their analysis is the inability to assess the familiarity between the moderator and the presenter. This is an important point to explore further since the power of familiarity between the moderators and the speakers cannot be underestimated. We would submit that, for many disease sites, the more senior the members become, the more likely they are to be known. This is supported by the authors' observation that the association of "nonprofessional" introductions was strongest in the melanoma/ sarcoma sessions, in which there are a relatively small circle of content experts. Indeed, for the authors to assume that a negative connotation such as "nonprofessional" or "biased" can be attributed to the more familiar introduction in the "familiar" situations may not be supported by any credible data and probably should be investigated first.

Nevertheless, the study does highlight that how a speaker is introduced could affect the audience's perception of that speaker and what is subsequently presented. Increasing awareness of these patterns is an important first step in recognizing our collective unconscious biases and could form the basis for actions to decrease professional marginalization at medical meetings. Prior work evaluating other professional meetings found that female speakers were more often introduced by first name only ${ }^{2}$, but here, Stewart et al. did not detail whether nonprofessional 
introductions at SSO meetings included the use of first names only or whether they were limited to not using the terms "Doctor" or "Professor" when appropriate.

While forms of address may signify credibility and respect, there are other important factors to consider. As such, there may have been some missed opportunities in these video reviews, and future work could be informed by a more formative evaluative process. Words do matter, and words can be powerful ${ }^{6}$. Respect comes in many forms, including the correct pronunciation of names and avoidance of microaggressions which could be subtly arrogant or condescending despite a proper introduction. Importantly, beyond formalities and the use of professional titles, tone and connotations of the words could be evaluated, especially when moderators are perceived as being disrespectful or demeaning. Using video feedback for moderators could highlight areas for improvement or be used as exemplars for best practices as long as the time spent giving and evaluating the introduction is not greater than the time spent giving and evaluating the scientific work!

Beyond the impact of hierarchy (and lack of association with gender), the authors also examined racial and ethnic diversity, noting the low representation of Black and Hispanic speakers at the meetings. The SSO program committee members score scientific abstracts in a blinded fashion, assessing the scientific merit of the abstract without knowledge of the authors' race, ethnicity, gender, institution, or country of origin. This is beyond the scope of the original data presented, but efforts to increase diversity do continue to focus on creating opportunities for our underrepresented members (and future members) to participate in scholarly and professional activities. Beyond diversity, insuring respect and professionalism promotes inclusion.
In summary, the authors are to be commended for their innovative utilization of video review. Assessment of behavior by video removes elements of recall bias and allows for a more complete analysis of performance. Through intentional work, we can fully evaluate and elucidate these aspects in the future and ensure equity, fairness, and a welcoming environment for all participants in scientific meetings.

DISCLOSURE The authors report no conflicts of interest.

\section{REFERENCES}

1. Stewart CL, De Andrade JP, Duma N, Ralph OK, Choong K, Gonzalez L, et al. Unconscious bias in speaker introductions at a surgical oncology meeting: hierarchy reigns over gender. Ann Surg Oncol. 2020. https://doi.org/10.1245/s10434-020-08906-8.

2. Duma N, Durani U, Woods CB, Kankeu Fonkoua LA, Cook JM, Wee $\mathrm{C}$, et al. Evaluating unconscious bias: speaker introductions at an international oncology conference. $J$ Clin Oncol 2019;37(36):3538-3545.

3. Hogg ME, Zenati M, Novak S, Chen Y, Jun Y, Steve J, et al. Grading of surgeon technical performance predicts postoperative pancreatic fistula for pancreaticoduodenectomy independent of patient-related variables. Ann Surg. 2016;264(3):482-91.

4. Jung JP, Zenati MS, Dhir M, Zureikat AH, Zeh HJ, Simmons RL, et al. Use of video review to investigate technical factors that may be associated with delayed gastric emptying after pancreaticoduodenectomy. JAMA Surg. 2018;153(10):918-27.

5. Jung JP, Zenati MS, Hamad A, Hogg ME, Simmons RL, Zureikat $\mathrm{AH}$, et al. Can post hoc video review of robotic pancreaticoduodenectomy predict portal/superior mesenteric vein margin status in pancreatic adenocarcinoma? HPB (Oxford). 2019;21(6):679-86.

6. Singletary B, Patel N, Heslin M. Patient perceptions about their physician in 2 words: the good, the bad, and the ugly. JAMA Surg. 2017;152(12):1169-70.

Publisher's Note Springer Nature remains neutral with regard to jurisdictional claims in published maps and institutional affiliations. 